\title{
Inhibitory effect of Patrinia on BRL-3A cell apoptosis through the TLR4/PI3K/AKT/GSK3ß and TLR4/P38/JNK signaling pathways
}

\author{
XIAOLI CHEN ${ }^{*}$, XIUPING YAN ${ }^{*}$ and LU GUO \\ Hepatopathy Department, Sixth People's Hospital of Qingdao, Qingdao, Shandong 266033, P.R. China
}

Received March 23, 2017; Accepted November 16, 2017

DOI: $10.3892 / \mathrm{mmr} .2018 .8466$

\begin{abstract}
The present study investigated the inhibitory effect of Patrinia on lipopolysaccharide (LPS)-induced apoptosis of rat liver BRL-3A cells. A Cell Counting Kit-8 assay was performed to measure the effect of Patrinia on BLR-3A cell activities. A biochemical assay was employed to detect the release of lactate dehydrogenase (LDH) in BRL-3A cells induced by different doses of LPS. Based on the release rate of $\mathrm{LDH}$, drug concentrations were set at $0.5,1$ and $2 \mathrm{~g} / \mathrm{l}$. Apoptotic morphology of cells was observed via Hoechst 33342 staining and flow cytometry was performed to detect apoptosis rates. Western blotting was performed to detect the expression of toll-like receptor 4 (TLR4), protein kinase B (AKT), phosphorylated $(\mathrm{P})-\mathrm{AKT}^{\mathrm{S} e r 473}$, glycogen synthase kinase $3 \beta$ (GSK3 $\beta$ ), P-GSK3 $\beta^{\text {Ser9 } 9}$, P38, P-P38, c-Jun N-terminal kinase (JNK), P-JNK, B-cell lymphoma-2 (Bcl-2), Bcl-2 associated $\mathrm{X}$ protein $(\mathrm{Bax})$ and active-caspase- 3 proteins. The translocation of GSK $3 \beta$ was observed by immunofluorescence staining. Results revealed that Patrinia increases cell activities and inhibits apoptosis. The expression levels of TLR4, P-P38 and P-JNK were reduced, whereas the expression of P-AKT ${ }^{\text {Ser473 }}$ and P-GSK3 $3 \beta^{\text {Ser9 }}$ were increased. Patrinia significantly reduced GSK $3 \beta$ nuclear translocation induced by LPS, and significantly decreased the mRNA expression levels of Bax/Bcl-2 and caspase-3 in BRL-3A cells induced by LPS. In conclusion, Patrinia may significantly reduce apoptosis of BRL-3A induced by LPS via the TLR4/PI3K/AKT/GSK3 $\beta$ and TLR4/P38/JNK signaling pathways, providing evidence for its potential use in liver disease therapy.
\end{abstract}

Correspondence to: Dr Lu Guo, Hepatopathy Department, Sixth People's Hospital of Qingdao, 9 Fushun Road, Qingdao, Shandong 266033, P.R. China

E-mail: guolu84yelei@163.com

${ }^{*}$ Contributed equally

Key words: Patrinia, toll-like receptor 4, glycogen synthase kinase $3 \beta$, phosphoinositide 3-kinase, protein kinase B, P38, c-Jun $\mathrm{N}$-terminal kinase, apoptosis

\section{Introduction}

In acute liver failure, hepatocellular death surpasses hepatocyte regeneration. Studies have revealed that hepatocellular death may be caused by a variety of biochemical signaling pathways, and the morphological alterations are characterized by large hepatocytes, necrosis or severe degeneration accompanied by a large amount of hepatocellular apoptosis, which occurs in response to viruses, drugs, ethanol, toxins and hemorrhagic lesions, followed by necrosis (1). A large amount of hepatocellular apoptosis and necrosis defines acute liver failure $(2,3)$. However, the underlying molecular mechanism of apoptosis in acute liver failure remains to be understood.

It is believed that the phosphoinositide-3 kinase (PI3K)/protein kinase B (AKT) signaling pathway mediates cell survival and a variety of biological effects, resulting in an anti-apoptotic effect $(4,5)$. Activated AKT may promote the phosphorylation of downstream substrates such as glycogen synthase kinase $3 \beta$ (GSK3 $\beta$ ) (12). Tournier et al (6) argued that the P38 and c-Jun N-terminal kinase (JNK) pathway is involved in apoptosis via mitogen-activated protein kinase (MAPK) signal transduction, and P38 also causes inflammatory responses. Activated JNK promotes apoptosis, and is involved in the regulation of apoptosis-associated gene expression and the activation of the caspase family, making it more complex than P38.

Patrinia is commonly used for reducing heat, detoxification, eliminating carbuncle abscess, reducing pain and dissipating blood stasis. It is a spicy and bitter heat-clearing herb, and may exhibit anti-viral, neuroprotective, heart-protective, antioxidant and anti-tumor effects (7). As it has a variety of pharmacological effects, Patrinia has attracted widespread attention. However, the inhibition of hepatocellular apoptosis and its underlying mechanism of liver failure have yet to be fully elucidated. The present study aimed to investigate the inhibitory effect of Patrinia on hepatocyte apoptosis in a rat model of acute liver failure, in order to provide experimental evidence for the prevention and treatment of acute liver failure with Patrinia. It was also determined whether this inhibition was mediated through the TLR4/PI3K/AKT/GSK $3 \beta$ and TLR4/P38/JNK signaling pathways.

\section{Materials and methods}

Materials. The rat liver BRL-3A cell line was provided by the Sun Yat-sen University cell bank (Guangzhou, China). Patrinia 
was purchased from Xi'an Four Seasons Biotechnology Co., Ltd. (Xi'an, China).

Cell Counting Kit-8 (CCK-8) assay to determine BRL-3A cell viability. To measure the effect of Patrinia on BRL-3A cell viability, BRL-3A cells were seeded at a density of $1 \times 10^{4}$ cells $/ \mathrm{ml}$ in 96 well plates for $48 \mathrm{~h}$ at $37^{\circ} \mathrm{C}$ in RMPI-1640 (Gibco; Thermo Fisher Scientific, Inc., Waltham, MA, USA), $10 \%$ fetal bovine serum (Gibco; Thermo Fisher Scientific, Inc.) and $1 \%$ streptomycin and penicillin. Cells were subsequently divided into five groups: The control group (treated with RPMI-1640), and Patrinia treated groups at concentrations of $0.25,0.5,1.0,2.0$ and $4.0 \mathrm{~g} / \mathrm{l}$. The wells of all groups were replaced with fresh medium and cells were cultured for a further $24 \mathrm{~h}$ at $37^{\circ} \mathrm{C}$. Cells were incubated with tetrazolium salt for $4 \mathrm{~h}$ and the absorbance in each well was subsequently measured at $450 \mathrm{~nm}$ with a microplate reader (Beijing Biocoen Biotechnology Co., Ltd., Beijing, China). The control group viability was set at $100 \%$ and BRL-3A cell viability of the Patrinia-treated groups were calculated accordingly.

To determine the effect of Patrinia on LPS-induced BRL-3A cell viability, BRL-3A cells were seeded at a density of $1 \times 10^{4}$ cells $/ \mathrm{ml}$ in 96 -well plates for $48 \mathrm{~h}$, and then divided into five groups: A, the normal group; B, the LPS-treated group; C, the low-density Patrinia (0.5 g/l)-treated group; D, the middle-density Patrinia (1 g/l)-treated group; E, the high-density Patrinia ( $2 \mathrm{~g} / \mathrm{l})$-treated group. Cells were pretreated with Patrinia for $2 \mathrm{~h}$ and then treated with LPS at $10 \mu \mathrm{g} / \mathrm{ml}$ for $24 \mathrm{~h}$, prior to determining the BRL-3A cell viability as described above.

Measuring the effect of Patrinia on lactate dehydrogenase ( $L D H)$ release by $L P S$ stimulation in BRL-3A cells via a biochemical method. BRL-3A cells $\left(1 \times 10^{4} / \mathrm{ml}\right)$ were seeded in 96-well culture plates for $24 \mathrm{~h}$, and grouped and treated as described above. LDH release in each BRL-3A cell was determined using a lactate dehydrogenase (LDH) kit (Genmed Scientifics, Inc., Wilmington, DE, USA). Cells were incubated with $\mathrm{LDH}$ reagent for $30 \mathrm{~min}$ at room temperature and absorbance was measured at $490 \mathrm{~nm}$ with a microplate reader.

Hoechst 33342 staining to observe the effect of Patrinia on apoptosis of BRL-3A cells after LPS stimulation. BRL-3A cell suspension was prepared and the cell density was adjusted to $1 \times 10^{4}$ cells $/ \mathrm{ml}$. The cells were cultured in 12-well culture plates with round coverslips. After incubation for $24 \mathrm{~h}$, the cells were fixed with $4 \%$ paraformaldehyde for $20 \mathrm{~min}$ and subsequently incubated with Hoechst stain solution $(1: 1,000$; Dojindo Molecular Technologies, Inc., Kumamoto, Japan) for $15 \mathrm{~min}$ at room temperature. Cells were observed with a fluorescent microscope (IX51; Olympus Corporation, Tokyo, Japan) at a magnification of $\mathrm{x} 100$.

Annexin V-fluorescein isothiocyanate (FITC)/propidium iodide $(P I)$ double labeling. Cells $\left(1 \times 10^{4} / \mathrm{ml}\right)$ were cultured in 6 -well plates for $24 \mathrm{~h}$. Cells were placed into a centrifuge tube, then digested with $0.25 \%$ EDTA-free trypsin (Gibco, Thermo Fisher Scientific, Inc.). Cells were collected and centrifuged at $447.2 \mathrm{x} \mathrm{g}$ for $5 \mathrm{~min}$ at $37^{\circ} \mathrm{C}$ and the supernatant was discarded before washing the cells with PBS twice. The cell density was adjusted to $5 \times 10^{5}$ cells $/ \mathrm{ml}$.
A total of $1 \mathrm{ml}$ cell suspension was centrifuged at $111.8 \mathrm{x} \mathrm{g}$ for $10 \mathrm{~min}$ at $4^{\circ} \mathrm{C}$ and the supernatant was discarded. A total of $1 \mathrm{ml}$ cold PBS was added and the cells were agitated for efficient suspension. The cells were centrifuged again at $111.8 \mathrm{xg}$ for $10 \mathrm{~min}$ at $4^{\circ} \mathrm{C}$ and the supernatant was discarded. The above procedure was repeated three or four times. The cells were re-suspended in $200 \mu \mathrm{l}$ binding buffer (cat. no. RVBB-02; Biomiga, Shanghai, China). Following this, the apoptotic rate was detected using an Annexin V-FITC apoptosis jut (Biouniquer Technology Co., Ltd., Hangzhou, China). A total of $10 \mu \mathrm{l}$ Annexin V-FITC was added and cells were agitated in the dark for $1 \mathrm{~min}$ at room temperature. Following the addition of a further $300 \mu \mathrm{l}$ binding buffer and $5 \mu \mathrm{l} \mathrm{PI}$, the apoptotic rate was measured by flow cytometry (BD FACS Calibur ${ }^{\mathrm{TM}}$; BD Biosciences, Franklin Lakes, NJ, USA). The experiment was repeated three times.

Western blot analysis. Cells were collected from all treatment groups and washed with PBS twice. A total of $400 \mu \mathrm{l}$ cell lysate was mixed with $40 \mu \mathrm{l} 10 \mathrm{mmol} / \mathrm{l}$ phenylmethylsulfonyl fluoride, gently agitated and put on ice for $10 \mathrm{~min}$ for sufficient lysis. The cells were gauged with sterile syringes repeatedly. The lysates were placed into Eppendorf tubes, placed on an ice-bath for $30 \mathrm{~min}$ and centrifuged at $12,000 \mathrm{x} \mathrm{g}$ at $4{ }^{\circ} \mathrm{C}$ for $15 \mathrm{~min}$. The supernatant was subsequently transferred to fresh Eppendorf tubes. Protein concentration was determined using a BCA protein assay kit. Protein sample $6 \mathrm{X}$ buffer (20 $\mu \mathrm{l}$; Beijing Biocoen Biotechnology Co., Ltd.) was added to each sample $(100 \mu \mathrm{l})$, boiled for $5 \mathrm{~min}$ and then stored at $80^{\circ} \mathrm{C}$. Protein $(30 \mu \mathrm{g} /$ lane $)$ was separated by $12 \%$ SDS-PAGE and transferred onto polyvinylidene difluoride membranes. The primary antibodies against toll-like receptor 4 (TLR4 (cat. no. 76B357; Novus Biologicals, LLC, Littleton, CO, USA), AKT (cat. no. 9272S; CST Biological Reagents Co., Ltd., Shanghai, China), phosphorylated (P)-AKT ${ }^{\text {Ser473 }}$ (cat. no. 9271S; CST Biological Reagents Co., Ltd.), GSK3 $\beta$ (cat. no. 9315S; CST Biological Reagents Co., Ltd.), P-GSK3 $\beta^{\text {Ser9 }}$ (cat. no. 9323S; CST Biological Reagents Co., Ltd.), P38 (cat. no. ab32142; Abcam, Cambridge, UK), P-P38 (ab47363, Abcam, USA), JNK (cat. no. ab110724; Abcam), P-JNK (cat. no. ab76572; Abcam), B-cell lymphoma-2 (Bcl-2; cat. no. S1460; Selleck Chemicals, Houston, TX, USA), Bcl-2 associated X protein (Bax; cat. no. S1076; Selleck Chemicals) and active-caspase-3 (cat. no. S7524; Selleck Chemicals) were added at a 1:1,000 dilution and incubated overnight at $4^{\circ} \mathrm{C}$. The cells were washed with PBS with $0.05 \%$ Tween (PBST) three times. Horseradish peroxidase-conjugated goat anti-rabbit IgG (cat. no. 01-15-06; 1:1,000; Sigma-Aldrich; Merck $\mathrm{KGaA}$ ) was added and incubated for $1 \mathrm{~h}$ at $4^{\circ} \mathrm{C}$. The cells were washed with PBST three times. Proteins were visualized using a chemiluminescence substrate (Merck KGaA). The expression levels of the above proteins were measured using the ChemiDox XRS+ system (version 4.6; Bio-Rad Laboratories, Inc., Hercules, CA, USA).

Effect of Patrinia on GSK3 $\beta$ translocation in BRL-3A cells after LPS stimulation. A BRL-3 cell suspension was prepared and the cell density was adjusted to $1 \times 10^{4}$ cells $/ \mathrm{ml}$. After incubation for $24 \mathrm{~h}$ in a 12-well culture plate with coverslips, cells were grouped and treated as described above. Following 
this, the coverslips containing cells were removed and immunofluorescence staining of GSK $3 \beta$ was performed. Cells were fixed in $4 \%$ paraformaldehyde for $30 \mathrm{~min}$ at room temperature and blocked with $1 \%$ bovine serum albumin (Santa Cruz Biotechnology, Inc., Dallas, TX, USA) for $20 \mathrm{~min}$ at room temperature. Cells were then incubated with GSK3 $\beta$ primary antibody (cat. no. 9315S; 1:500; CST Biological Reagents Co., Ltd.) for $12 \mathrm{~h}$ at $4^{\circ} \mathrm{C}$ followed by incubation with Alexa Fluor ${ }^{\circledR}$ 488 Donkey Anti-Rabbit IgG (H+L) secondary antibody (cat. no. A121206; Invitrogen; Thermo Fisher Scientific, Inc.) at $37^{\circ} \mathrm{C}$ for $1 \mathrm{~h}$. GSK3 $\beta$ nuclear translocation was observed and images were captured using a IX51 fluorescence microscope (Olympus Corporation).

Statistical analysis. Data are expressed as mean \pm standard deviation of three independent experiments. Comparison between two groups was performed via a Student's t-test, whereas comparisons between $>2$ groups was determined by a one-way analysis of variance followed by Tukey's post-hoc test for multiple comparisons. $\mathrm{P}<0.05$ was considered to indicate a statistically significant difference. Data were analyzed using GraphPad Prism version 5.0 software (GraphPad Software, Inc., La Jolla, CA, USA).

\section{Results}

Effect of Patrinia on BRL-3A cell viability. The CCK-8 assay was used to determine the effect of Patrinia on the viability of BRL-3A cells. BRL-3A cells were cultured in medium containing different concentrations of Patrinia for $24 \mathrm{~h}$. The results demonstrated that the cell viability was $100 \%$ in the control group. Compared with the control group, the Patrinia-treated groups did not show cytotoxicity, suggesting that the subsequent inhibitory effect of Patrinia was not due to its cytotoxicity (Fig. 1).

Effects of Patrinia on the viability of BRL-3A cells after LPS stimulation. The CCK- 8 assay was used to determine the effect of Patrinia on the viability of BRL-3A cells after LPS stimulation. The results revealed that the cell viability of the LPS-stimulated group decreased significantly compared with the control group. However, compared with the LPS-stimulated group, the cell viability of the Patrinia-pretreated groups increased in a dose-dependent manner (Fig. 2).

Effect of Patrinia on the release of $L D H$ in $B R L-3 A$ cells after LPS stimulation. The release of LDH was an indicator of toxicity of BRL-3A cells after LPS stimulation. The results demonstrated that, compared with the control group, LDH release was significantly increased in the LPS-stimulated groups. However, pre-treatment with Patrinia significantly reduced LDH release, in a dose-dependent manner (Fig. 3).

Morphological effects of Patrinia on BRL-3A cell apoptosis after LPS stimulation. Fluorescence microscopy was employed to observe the morphological features of apoptosis. The control group exhibited normal nucleus morphology and nuclear membrane integrity, with no signs of apoptosis. The LPS group displayed enhanced staining of apoptotic cells and nuclear debris and pyknosis were observed. The fluorescence

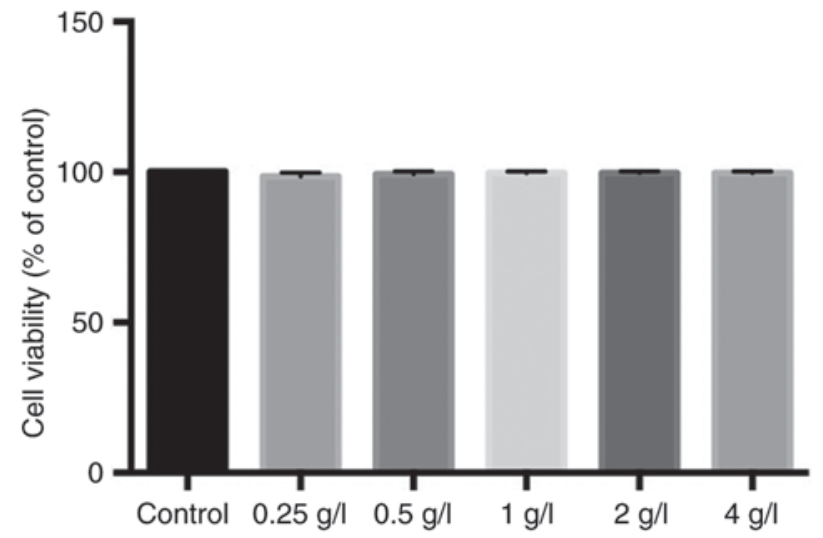

Figure 1. Effect of Patrinia on BRL-3A cell viability. Cells were treated with $0.25,0.5,1,2$ or $4 \mathrm{~g} / 1$ Patrinia or with media alone as a control, prior to determining cell viability by a Cell Counting Kit- 8 assay.

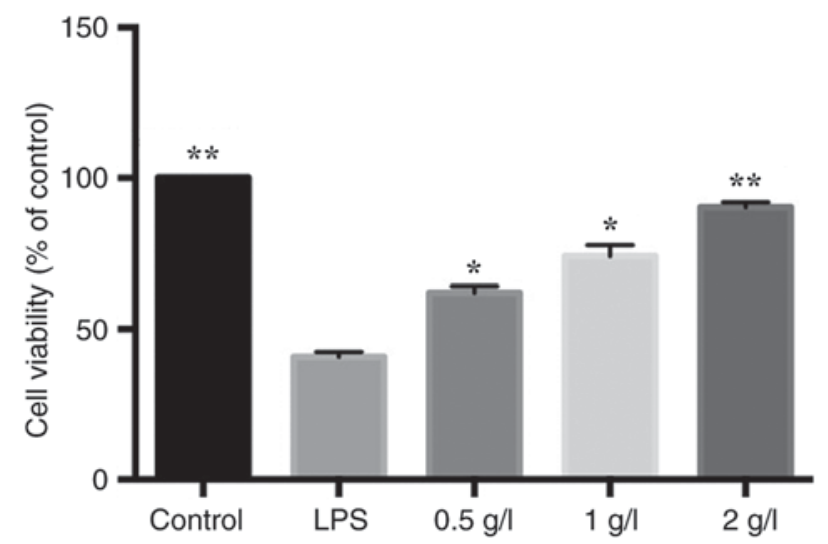

Figure 2. Effects of Patrinia on the cytotoxicity of BRL-3A cells after LPS stimulation, as determined by the Cell Counting Kit- 8 assay. ${ }^{*} \mathrm{P}<0.05$, ${ }^{* *} \mathrm{P}<0.01$ vs. LPS. LPS, lipopolysaccharide.

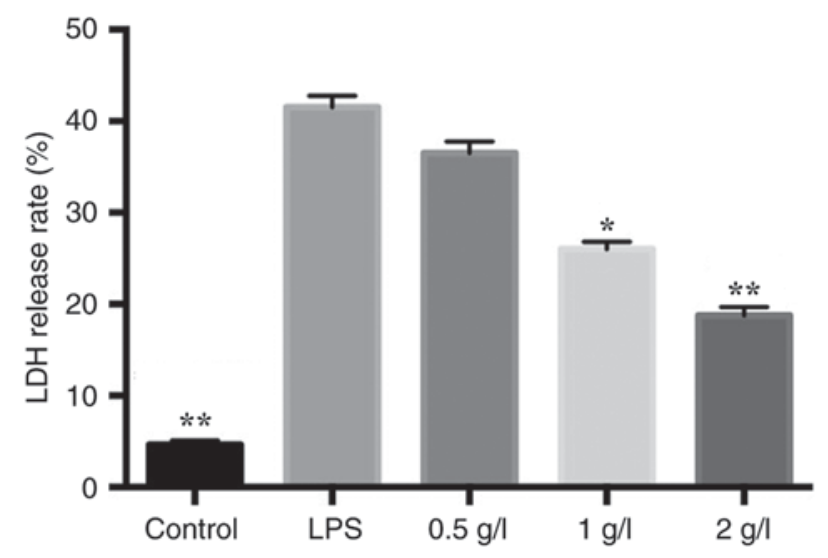

Figure 3. Effects of Patrinia on the release of LDH in BRL-3A cells after LPS stimulation. ${ }^{*} \mathrm{P}<0.05,{ }^{* * *} \mathrm{P}<0.01$ vs. LPS. LDH, lactate dehydrogenase; LPS, lipopolysaccharide.

intensity of the Patrinia-treated groups appeared to be lower, suggesting a reduced number of apoptotic cells (Fig. 4).

Effect of Patrinia on apoptosis of BRL-3A cells after LPS stimulation. Flow cytometric analysis demonstrated that 


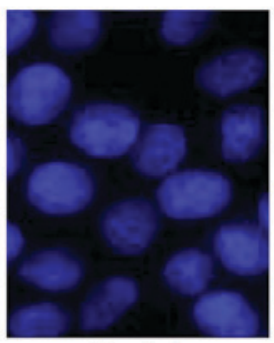

Control

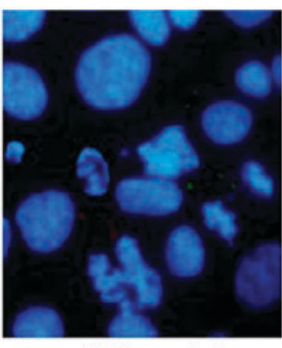

LPS model

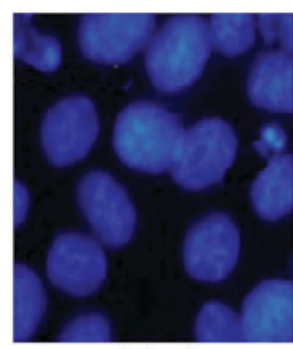

$0.5 \mathrm{~g} / \mathrm{l}$

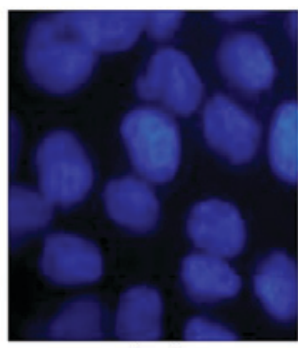

$1 \mathrm{~g} / \mathrm{l}$

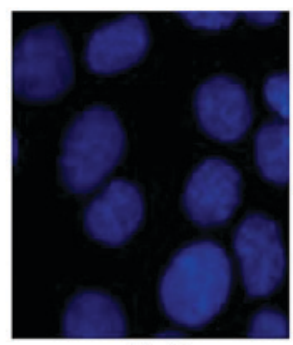

$2 \mathrm{~g} / \mathrm{l}$

Figure 4. Morphological effects of Patrinia on BRL-3A cells after LPS stimulation, as determined by Hoechst staining
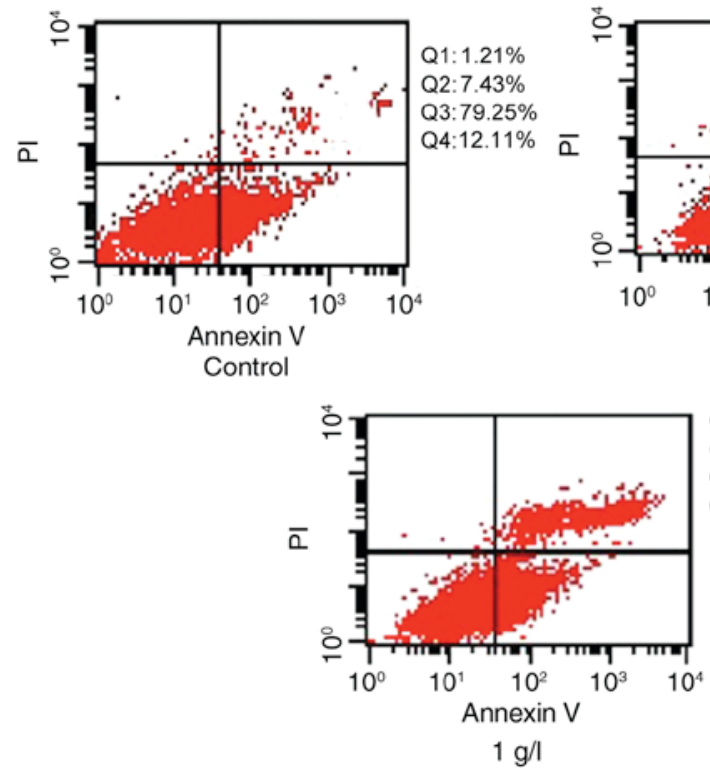
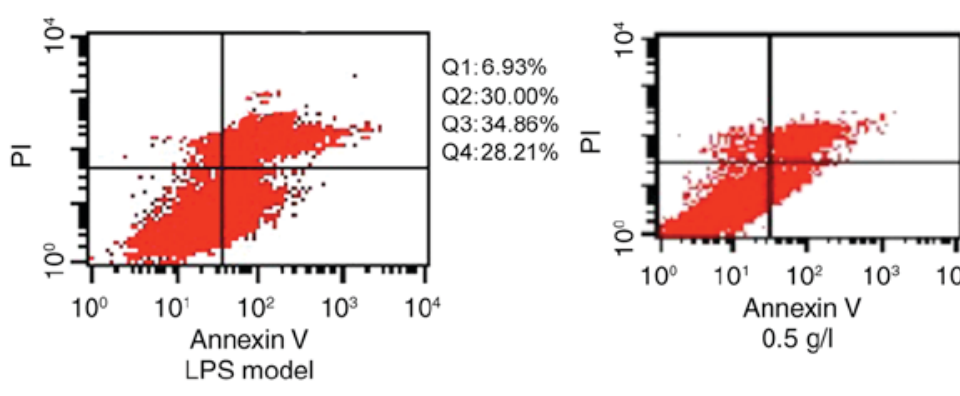

Q1: $8.55 \%$ Q2: $25.69 \%$ Q3: $40.73 \%$ Q4: $25.03 \%$

Figure 5. Annexin V-FITC/PI double labelling of BRL-3A cells for the detection of apoptosis, after treatment with or without Patrinia or LPS. FITC, fluorescein isothiocyanate; PI, propidium iodide; LPS, lipopolysaccharide.

apoptosis of BRL-3A cells in the LPS group was significantly higher compared with the control group. However, the Patrinia-treated groups exhibited reduced apoptosis of BRL-3A cells induced by LPS, with a statistical significance (Fig. 5).

Western blotting to detect the expression levels of TLR4, $A K T, P-A K T^{\text {Ser } 473}, G S K 3 \beta, P-G S K 3 \beta^{\text {Ser } 9}, P 38, P-P 38, J N K$, $P-J N K, B a x, B c l-2$ and active-caspase- 3 proteins. The results revealed that the expression levels of TLR4, P-P38, P-JNK, Bax and active-caspase-3 were reduced by treatment with Patrinia, whereas the expression of P-GSK $3 \beta^{\text {Ser9 }}$, $\mathrm{P}-\mathrm{AKT}^{\mathrm{Ser} 473}$ and $\mathrm{Bcl}-2$ were increased, compared with the LPS group (Fig. 6A-C).

Effects of Patrinia on GSK3 $\beta$ translocation in BRL-3A cells after LPS stimulation. Immunofluorescence staining was performed to observe the nuclear translocation of GSK3 $\beta$, which was localized primarily in the cytoplasm (green fluorescence) in the control group. After $24 \mathrm{~h}$ of LPS stimulation, the majority of the GSK $3 \beta$ may have translocated to the nucleus, as the green fluorescence appeared to be co-localized with the blue nucleus. Compared with the LPS group, the
Patrinia-treated groups exhibited a decrease in GSK3 $\beta$ nuclear translocation (Fig. 7).

\section{Discussion}

TLR4 is a member of the TLR family and is a pattern-recognition receptor (8). Studies have demonstrated that TLR4 expression is increased in liver injury and acute liver failure (9).

The PI3K/AKT signaling pathway is an important regulator of cell survival and apoptosis (10). PI3K is a conservative signal transduction enzyme, involved in regulating cell proliferation and inhibiting apoptosis (11). PI3K is an enzyme complex consisting of a regulatory subunit (p85) and a catalytic subunit (p110) (12). Activation of PI3 K may promote the formation of a secondary messenger, phosphatidylinositol (3-5)-triphosphate, which activates AKT phosphorylation. Activated AKT may then activate or inhibit its downstream substrates, including the phosphorylation of GSK3, thereby regulating cell proliferation, differentiation, apoptosis and migration processes (13-15). AKT may also inhibit apoptosis by inhibiting the release of cytochrome $\mathrm{c}$ via the suppression of Bax activities, and also by phosphorylating Bcl-2 at Ser136 

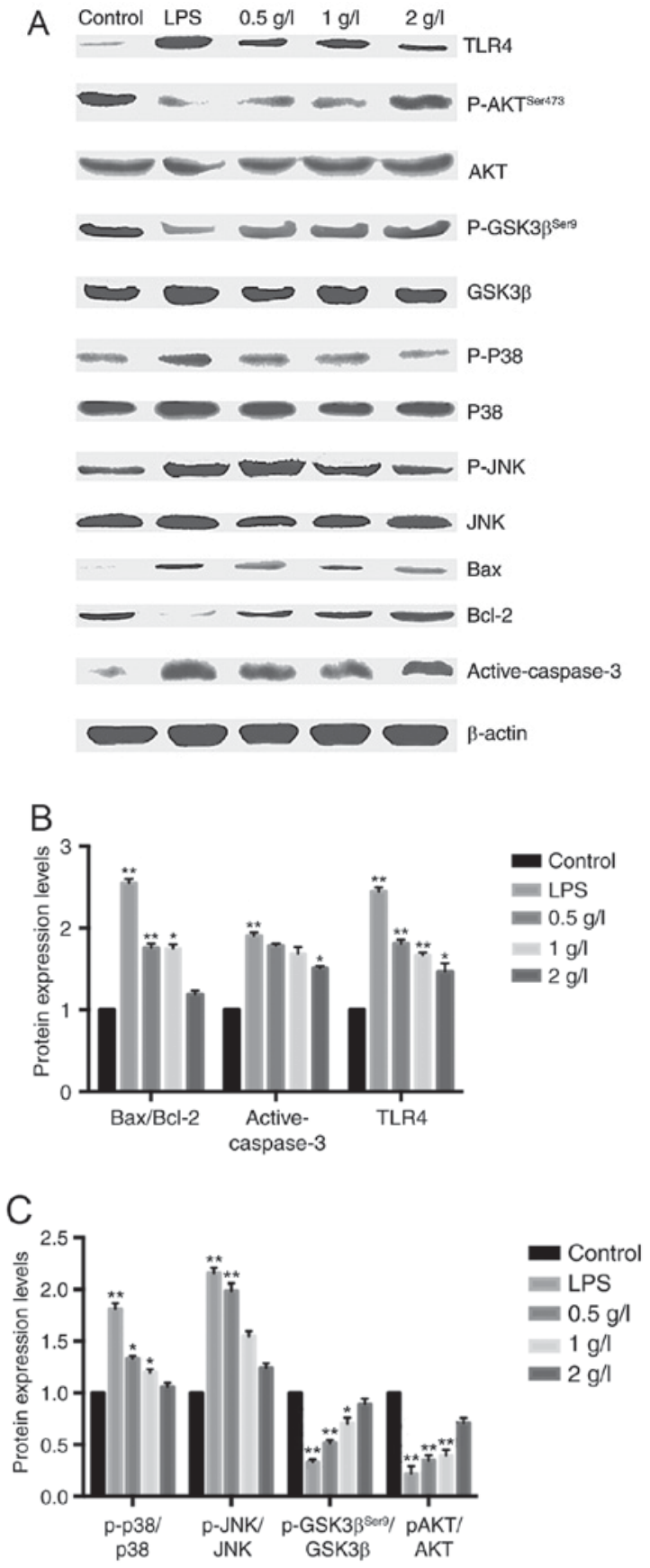

Figure 6. The effect of Patrinia on the expression levels of various apoptosis-associated proteins, following LPS stimulation. (A) Western blotting and (B and $\mathrm{C}$ ) densitometric analysis. ${ }^{*} \mathrm{P}<0.05,{ }^{* *} \mathrm{P}<0.01$ vs. LPS. LPS, lipopolysaccharide.

site to prevent the inhibition of B-cell lymphoma extra-large. In the present study, the underlying mechanism of Patrinia inhibition of BRL-3A cell apoptosis was investigated. Western blotting was performed to detect the expression levels of certain proteins. The expression of TLR4 in BRL-3A cells was significantly increased by LPS stimulation, the expression of P-AKT ${ }^{\text {Ser } 473}$ and P-GSK $3 \beta^{\text {Ser9 }}$ was decreased by LPS, and the PI3K/AKT/GSK3 $\beta$ signaling pathway was activated. However, treatment with Patrinia reduced the expression of TLR4 induced by LPS, and promoted the phosphorylation of AKT and GSK3 $\beta$. This suggested that Patrinia inhibited LPS-induced apoptosis of BRL-3A cells.
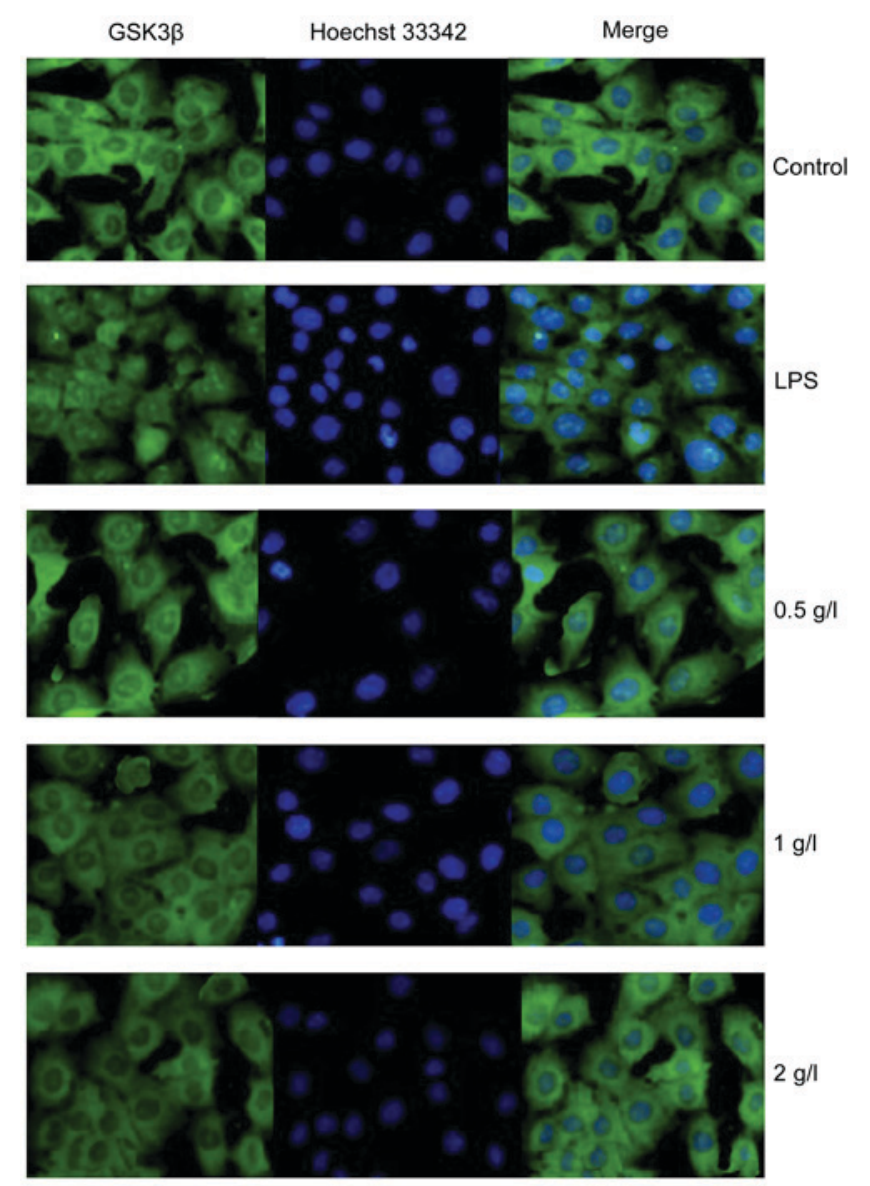

Figure 7. Effect of Patrinia on GSK3 $\beta$ nuclear translocation following LPS stimulation. Cells were immunostained for GSK3 $\beta$ and nuclei were stained with Hoechst 33342. LPS, lipopolysaccharide; GSK3 $\beta$, glycogen synthase kinase $3 \beta$.

MAPK, as a signal transporter, carries external signals to the nucleus, and mediates a number of biological effects, including cell proliferation, differentiation and apoptosis, via a series of protein kinase cascade reactions. Studies have demonstrated that the MAPK signaling pathway includes P38 and JNK signaling pathways (16). p38 is a $38 \mathrm{kDa}$ protein consisting of 360 amino acids, which belongs to the stress protein kinase family. It has been revealed that P38 has five isomers. The P38 pathway may be activated by inflammatory factors, such as tumor necrosis factor and interleukin-1, stress stimuli such as UV light, hypoxia and heat shock, as well as LPS and gram-positive bacterial cell wall components. The phosphorylation of P38 indicates its activation (17).

JNK is a serine/threonine protein kinase identified in 1990 (18). In mammalian cells, JNK in encoded by the JNK1, $J N K 2$ and $J N K 3$ genes. Cell model studies have shown that activation of the JNK pathway is involved in the initiation of apoptosis induced by various stimuli. JNK activation is involved not only in drug-induced apoptosis, but also in DNA damage-induced apoptosis (19). P-JNK, the phosphorylated product of JNK, indicates the activation of JNK.JNK is activated in the presence of inflammatory factors, such as heat shock, ionizing radiation, oxidative stress and DNA damage $(20,21)$. JNK may phosphorylate a variety of transcription factors, such as JNK, p53 and ETS domain containing protein Elk-1, 
which have been involved in the expression of genes associated with cell proliferation and apoptotic processes. In the present study, BRL-3A cells were stimulated with LPS, and western blotting was performed to detect the expression levels of P38, JNK and their phosphorylated proteins. LPS increased the expression levels of phosphorylated P38 and JNK proteins, suggesting that the activation of P38 and JNK promote apoptosis of BRL-3A cells. However, the phosphorylation levels of JNK and P38 in BRL-3A cells were significantly reduced by Patrinia treatment; thus apoptosis of BRL-3A cells was inhibited. The inhibition of LPS-induced BRL-3A cell apoptosis by Patrinia was associated with a decrease in P-JNK and P-P38 expression. Patrinia may serve an anti-apoptotic role through inhibition of the TLR4/P38/JNK signaling pathway.

In conclusion, treatment with Patrinia may reduce apoptosis of BRL-3A cells induced by LPS. Through inhibition of the expression levels of TLR4 in BRL-3A cells, Patrinia increased the expression of P-AKT $\mathrm{T}^{\mathrm{Ser} 473}$ and P-GSK $3 \beta^{\text {Ser9 }}$, decreased GSK3 $\beta$ nuclear translocation, reduced P38 and JNK phosphorylation levels and decreased Bax/Bcl-2 ratio and caspase- 3 expression. Therefore, Patrinia may inhibit BRL-3A cell apoptosis via the TLR4/PI3 K/AKT/GSK3 $\beta$ and TLR4/P38/JNK signaling pathways. However, further research is required to quantitatively confirm that Patrinia treatment in LPS-stimulated BRL-3A cells leads to GSK3 $\beta$ nuclear translocation, as this was determined by eye in the present study. In conclusion, evidence was provided for the effects of TLR4-mediated signaling on hepatocyte apoptosis in acute liver failure, and targeting of this signaling may aid in the development of effective drugs for the prevention and treatment of hepatocyte apoptosis in acute liver failure.

\section{References}

1. Lopez M, Kopec AK, Joshi N, Geddings JE, Cline H, Towery KL, Rockwell CE and Mackman N: Fas-induced apoptosis increases hepatocyte tissue factor procoagulant activity in vitro and in vivo. Toxicol Sci 141: 453-464, 2014

2. Jiang $X$ and Wang $X$ : Cytochrome $\mathrm{c}$ promotes caspase-9 activation by inducing nucleotide binding to Apaf-1. J Biol Chem 275: 31199-31203, 2000.

3. Tait SW and Green DR: Mitochondria and cell death: Outer membrane permeabilization and beyond. Nat Rev Mol Cell Biol 11: 621-632, 2010.
4. Fulda S: Modulation of mitochondrial apoptosis by PI3K inhibitors. Mitochondrion 13: 195-198, 2013.

5. Johnson-Farley NN, Patel K, Kim D and Cowen DS: Interaction of FGF-2 with IGF-1 and BDNF in stimulating Akt, ERK, and neuronal survival in hippocampal cultures. Brain Res 1154: 40-49, 2007.

6. Tournier C, Hess P, Yang DD, Xu J, Turner TK, Nimnual A, Bar-Sagi D, Jones SN, Flavell RA and Davis RJ: Requirement of JNK for stress-induced activation of the cytochrome c-mediated death pathway. Science 288: 870-874, 2000.

7. Zhang YF: The research progress of Patrinia. J Chin Med Mat 1: 148-152, 2009 (In Chinese).

8. Du C, Fang M, Li Y, Li L and Wang X: Smac, a mitochondrial protein that promotes cytochrome $\mathrm{c}$-dependent caspase activation by eliminating IAP inhibition. Cell 102: 33-42, 2000.

9. Mohammadi A, Tajik N, Shah-Hosseini A, Alavian SM, Sharifi Z and Jarahi L: FAS and FAS-ligand promoter polymorphisms in hepatitis B virus infection. Hepat Mon 15: e26490, 2015.

10. Muzio M, Chinnaiyan AM, Kischkel FC, O'Rourke K, Shevchenko A, Ni J, Scaffidi C, Bretz JD, Zhang M, Gentz R, et al: FLICE, a novel FADD-homologous ICE/CED-3-like protease, is recruited to the CD95 (Fas/APO-1) death-inducing signaling complex. Cell 85: 817-827, 1996.

11. Flanagan L, Sebastià J, Tuffy LP, Spring A, Lichawska A, Devocelle M, Prehn JH and Rehm M: XIAP impairs Smac release from the mitochondria during apoptosis. Cell Death Dis 1: e49, 2010.

12. Chen HC, Kanai M, Inoue-Yamauchi A, Tu HC, Huang Y, Ren D, Kim H, Takeda S, Reyna DE, Chan PM, et al: An interconnected hierarchical model of cell death regulation by the BCL-2 family. Nat Cell Biol 17: 1270-1281, 2015.

13. Gross A: BCL-2 family proteins as regulators of mitochondria metabolism. Biochim Biophys Acta 1857: 1243-1246, 2016.

14. Martinou JC and Youle RJ: Mitochondria in apoptosis: Bcl-2 family members and mitochondrial dynamics. Dev Cell 21: 92-101, 2011.

15. Ha H, Han D and Choi Y: TRAF-mediated TNFR-family signaling. Curr Protoc Immunol Chapter 11: Unit11.9D, 2009.

16. Weichhaus M, Chung ST and Connelly L: Osteoprotegerin in breast cancer: Beyond bone remodeling. Mol Cancer 14: 117, 2015.

17. Guicciardi ME, Malhi H, Mott JL and Gores GJ: Apoptosis and necrosis in the liver. Compr Physiol 3: 977-1010, 2013.

18. Yarza R, Vela S, Solas M and Ramirez MJ: c-Jun N-terminal kinase (JNK) signaling as a therapeutic target for alzheimer's disease. Front Pharmacol 6: 321, 2016.

19. Kim YR, Kang TW, To PK, Xuan Nguyen NT, Cho YS, Jung C and Kim MS: HOXB13-mediated suppression of p21WAF1/CIP1 regulates JNK/c-Jun signaling in prostate cancer cells. Oncol Rep 35: 2011-2016, 2016.

20. Hengartner MO: The biochemistry of apoptosis. Nature 407: 770-776, 2000

21. Ma M, Wang L, Ma Y, Yang Y, Chen B and Zhu X: Effects of norepinephrine on proliferation and apoptosis of neonatal cardiac fibroblasts in rats. Zhonghua xin xue guan bing za zhi 43: 542-547, 2015 (In Chinese). 